\title{
Ich bin dafür
}

_ Länder wie die Niederlande, Großbritannien, Australien und die USA haben ihn längst: den Direktzugang zur Physiotherapie. Ich persönlich würde ihn für Deutschland ebenfalls sehr begrüßen. Die Physiotherapie entwickelt sich zur Profession. Sie hat in allen Fachgebieten ein Expertenwissen aufgebaut, das die Mediziner heute nicht mehr überblicken können. Die wenigsten Ärzte sind in Funktionsdiagnostik gut ausgebildet, können deshalb gerade bei muskuloskeletalen Schmerzen keine strukturierte Therapie verordnen und sind auf die Verordnungskrücke Heilmittelkatalog angewiesen.

_ Als Gegenargument ist häufig zu hören, die Physiotherapeuten

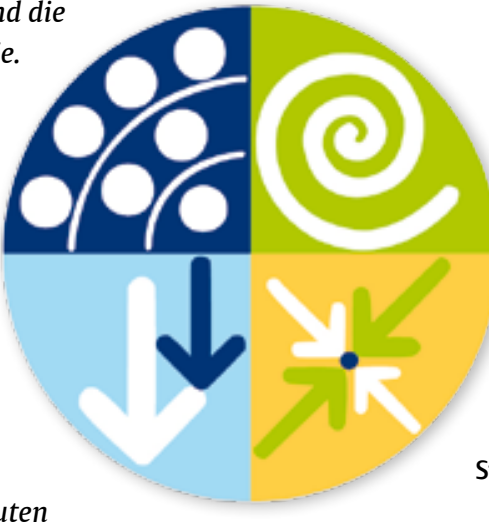
seien nicht ausreichend für den Direktzugang qualifiziert. In manchen Punkten ist das bislang so. Doch wir könnten dem Weg der Niederlande folgen, die bei der Einführung alle Physiotherapeuten in einem Wochenendkurs in Screeningmethoden nachqualifiziert haben und die Inhalte inzwischen in der Ausbildung vermitteln.

_ Bei manchen Therapeuten überwiegt vielleicht die Angst vor dem Risiko, etwas zu übersehen. Doch nobody is perfect, auch bei den Ärzten nicht. Und wer sich nicht qualifiziert genug für den Direktzugang fühlt, ist nicht gezwungen, ihn anzubieten. Wir dürfen den Patienten zutrauen, dass sie sehr wohl differenzieren können, wo sie sich gut aufgehoben fühlen und wo nicht. Sie haben ja die freie Wahl: Sie können direkt den Physiotherapeuten aufsuchen oder den Weg über den Arzt gehen.

_ Ich freue mich auf die Podiumsdiskussion zum Direktzugang am 29. Januar 2016 auf dem 10. physiokongress in Stuttgart. Wollen Sie mitdiskutieren? Dann schauen Sie auf Seite 21, bewerben Sie sich und gewinnen Sie eine Freikarte für den physiokongress.

Ihre
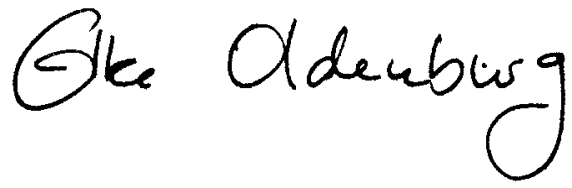

Direktzugang zum Physiotherapeuten - wie stehen Sie dazu? Diskutieren Sie mit auf dem 10. physiokongress am 29. Januar 2016 in Stuttgart. 2-mal „Maitland“

1-mal „ComplexCore+-

Rumpfstabilisation in

Training und Therapie“

Seite 48

In jeder physiopraxis werden attraktive Gewinne verlost. Möchten Sie einen ergattern, klicken Sie unter www.thieme.de/physiopraxis auf „Gewinnspiel“.

Und das gibt es in dieser Ausgabe zu gewinnen:

und außerdem ...

1 Jahresabo der neuroreha Seite 14 3 Gutscheine zur

Verschönerung Ihrer Praxis Seite 64 10 Apps und 1 Jahres-

lizenz der Software

„ComplexCore+“" 